\title{
EARLY CHILDHOOD IDENTITY: ETHNICITY AND ACCULTURATION
}

\author{
MARIA DAN \\ Faculty of Psychology and Educational Sciences, \\ University of Bucharest \\ 90 Panduri Boulevard, Bucharest, Romania \\ E-mail address: maria_cristina_popa@yahoo.ca
}

\begin{abstract}
How are concepts such as ethnic identity, acculturation and cultural orientation being perceived by a child? What is the process of identity construction in early preschool age? How is children's wellbeing affected by parents' desire to expose them to a certain culture, other than the one the children were born into? How natural is learning a foreign language for children, given a multiethnic space characterized by adversity and disparities such as "them"-"us"? And what are the potential outcomes of the phenomena in question? These are a few questions that the current study reflectively followed up upon by using a qualitative research design and data triangulation in order to increase its validity. The SDQ Questionnaire used to study the children's wellbeing, the semi-structured "in-depth" interviews conducted on the main early preschool identity builders in the Cristian community and the participative observation indicated the children were proud to be part of the German department group. They did not undergo a brutal process of affiliation to the Saxon ethnicity due to the educators' various compromises, and their wellbeing didn't seem to be affected at the SDQ administration stage. However, learning German proved to be a difficult process and the two potential outcomes included hitting the language barrier or resuming adaptation to the native ethnic code. This study highlights the impact of the cultural code on the early identity foundation.
\end{abstract}

Key words: Ethnic identity, acculturation, child wellbeing, belonging

\section{INTRODUCTION \\ ETHNIC IDENTITY, ACCULTURATION AND CULTURAL ORIENTATION}

Ethnic identity defines the degree to which an individual perceives oneself as a member of a specific ethnic group. Acculturation, as briefly described, is the process of one's affiliation to a culture different from the one that the individual is born into. While cultural orientation represents individual perception and the extent of adherence to different cultures.

Recent studies indicate certain common structures underlying the general view on ethnic identity. According to Jean S. Phinney $(1990,1992)$, ethnic identity development involves two interdependent mechanisms: exploration and affirmation/belonging. 
Exploration refers to the behavioral aspects of ethnic identity through which individuals make continuous efforts to learn data about their ethnic group, its history and that of its culture and to talk to other members as to find out the group rules, the customs and the values specific to the ethnicity (Phinney, 1990). The identity communication theory suggests that such interactive approaches stand for important aspects of identity, inseparable from the innate sense of belonging (Hecht, Warren, Jung \& Krieger, 2005).

Affirmation/Belonging refers to the psychological aspects of ethnic identity, including the emotional feelings and the cognitive perceptions attached to a single group (J. S. Phinney, 1990). The desire of belonging is one of the basic human needs (Baumeister \& Leary, 1995; Maslow, 1970) and therefore, group identity constitutes an important self concept (Tajfel \& Turner, 1986).

Usually, individuals are exposed to the customs and rules of their ethnic group at an early stage, through child-parent contact (Kagitcibasi, 1996) and therefore face the silent, yet powerful encouragement to internalize values and views upon the group frame. In contrast to belonging, exploration requires voluntary efforts to seek ethnic roots, and generally occurs later on (French et al., 2006).

Acculturation may occur in the process of building the ethnic identity, modifying the two development mechanisms thereof. The multiethnic space per se determines the development of identity. Here, in the multi-ethnicity zone, exploration and belonging have other dimensions. They may increase the efforts for obtaining accurate information about the ethnic group, and passing on the customs and rules may be influenced by a desire to become oriented towards ethnic groups which bring about material opportunities.

\section{IMPLICIT CULTURE AND ACCULTURATION}

David Wong (2006) describes the process of ethnic identity knowledge as the path upon which an individual is being led by the groups of belonging towards developing a desirable behavior, according to their standards. Within this process, a very important role is held by the cultural heritage. It is "an organization of reality, a logic accepted and disseminated by the members of the community. It requires a set of views and beliefs that are virtually indisputable and which, if sustained by convictions, have the force of evidence and the virtue of the absolute" (Zarate, 1986, p. 19).

The contact between cultures is a particularly complex process. Interculturality is the set of processes through which individuals or groups interact. These groups belong to two or more sets that claim different cultures or may relate to distinct cultures (Clanet, 1993, p. 70). In an attempt to understand and approach otherness, it is necessary to cover several steps:

- The subject expresses in his/her specific code. Faced with a new code, he/ she translates the new one according to the known data. The new code is being assimilated into the old one.

- However, the subject realizes that his/her own cultural code turns out unable to express the data of the new reality. The subject adheres to the 
cultural code of another, thus he/she will assimilate the new code or the new code will assimilate the subject.

- The imbalance or the conflict generated by the presence of two different codes may entail the search of mediation, an attempt to create a symbol of union between the two codes. In this case, the subject produces a critical distance by developing a speech and taking the position of researcher of cultural sets. The cultural codes with which he/she operates may become relative.

- The subject will compare the realities of the two cultural codes, by placing himself/herself either into one code, or into the other, or into one independent of them. A kind of a third cultural space is being created (a sort of meta-code or meta-culture), which borrows a bit of each of the two reference codes.

We note that the first step reduces the other to its own cultural code. The bases of the first cultural code, in terms of education, are imposed by the family, then by education (starting with pre-school), the media, the church, etc.

\section{ETHNIC IDENTITY, ACCULTURATION AND LANGUAGE}

There are two theories that provide explanations for the link between the use of language, cultural adaptation and ethnic identity. The ethnolinguistic identity theory (ELIT) suggests that language is a defining aspect of social group identity (Giles \& Johnson, 1987; Giles, Williams, Mackie \& Rosselli, 1995). Thus, the individual's perceptions of the surrounding culture and his/her heritage culture influences one's preference for language and use of language (Giles et al., 1995; Phinney et al., 2001).

The theory of subjective ethnolinguistic vitality (Bourhis \& Sachdev, 1984; Giles, Bourhis \& Taylor, 1977) draws attention upon the impact of the social factors. One of these factors would be the language of minority members. John Gibbons and Elizabeth Ramirez (2004) found that, among the Hispanic teenagers living in Sydney, the determination to resist the social pressure of being assimilated into the local English community is associated with speaking the Spanish language and maintaining the sense of ethnic pride. These findings, based on the ELIT and the SEV, suggest that language behavior is related to cultural orientation, ethnic identity and the local environment.

\section{BELONGING AND ACCULTURATION THROUGH EARLY CHILDHOOD EDUCATION}

The experience of belonging is an integral part of the human existence. Since the beginning of his/her life, the individual needs to define the sense of belonging and affiliation. Children are primarily part of a family, then an ethnic-cultural group. The two entities may overlap by description or may, in some cases, have contradictory features. Belonging is necessary for the interdependency of children in relation to others and for the health of the relationships that lead to a definition of identity. During childhood, the relationships established by children are crucial to their sense of belonging. Clarifying the source of belonging and assuming it are decisive for constructing adult identity. 


\section{CHILD WELLBEING}

Wellbeing is generally understood as the quality of people's lives. Even though the different domains and measures employed make it difficult to make comparisons of childhood wellbeing across different studies and different contexts, there is some emerging consensus that childhood wellbeing is multi-dimensional and should include dimensions of physical, emotional and social wellbeing; should focus on the immediate lives of children but also consider their future lives; and should incorporate some subjective as well as objective measures (Statham \& Chase, 2010, p. 2).

As remains to be seen, in this paper we are interested in children's state of wellbeing in the process of identity construction. More specific, we focus on their emotional reactions in a cultural educational environment, different from the family one. In order to measure this, we used the SDQ Questionnaire.

\section{THE EARLY CONSTRUCTION OF ETHNIC IDENTITY IN A MULTIETHNIC SPACE. A CASE STUDY ON THE ROMANIAN- SAXON COMMUNITY FROM VULCAN, BRAŞOV, ROMANIA}

The Context of the Study

Transylvania or Ardeal (the German Siebenbürgen) is one of the historical regions of Romania located inside the Carpathian Mountains' arch. The many historical marks, the mix of population, of the cultural elements, from architecture to behavior, the sometimes problematic dualities, are actual evidence of the multiethnic Transylvanian space.

Cristian is a locality in Braşov county, Transylvania, one of the 240 Saxon villages over the territory of Romania. The demographic movement in Cristian, beginning with the records taken in 1838 and up until 1992, shows an inversely proportional relation between the Romanian population - the Saxon population, of importance for the article and the phenomena in question.

The relationship them-us regarding the Saxons and the Romanians goes back over 800 years. Before the formation of national states, the Saxons were considered a people in Transylvania. Nowadays, in the areas they still reside in, they are a minority. Where there are ethnic dualities, comparisons between the features of the representatives are inevitable. They have qualities detrimental to $u s$, and vice versa. When lawful and actual dominion is brought into discussion, this game of arguments in terms of rule is inevitable. As concerns Saxons and Romanians, the descriptive differences place the qualities of the Saxon ethnicity in a favorable light. As remains to be seen, the Saxon quality of work, the good organization, the rigor, the efficiency, the high German education level are features attributed to the Saxon ethnicity.

The entire village of Cristian, as well as the surrounding ones, bears the Saxon mark. Highly interesting is the good preservation and maintenance of the houses, institutions and the overall village appearance, given that the number of the Saxons is currently below 80 . Although so few have remained, their influence is 
still being felt, and there is that something that still makes the inhabitants (mostly Romanians) keep the memory of the Saxons alive.

\section{Purpose of Study}

We considered it necessary to pinpoint the historical, geographical and attitudinal frame, so to better understand the phenomenon of signing up Romanian children for the German school department. Throughout the entire Transylvanian area, the German School is seen as an elite school, towards which, evidently, are being directed the children of the ethnic group, but also children from Romanian families. The elitism does not only come from studying the German language. The German School is a concept of quality of education and a catalyst for chance, and the study language is merely the debut frame or the path to access the values perceived by Romanian parents.

In recent years, where there is a German department in a school (and in the concerned area there are numerous German or Romanian schools with classes taught in German), competition for a place in the German department is notable. Romanian parents aim to sign their children up on one of the German-teaching spots so that by learning the language, they would have access to all of the opportunities provided by the German School.

Therefore, the purpose of this qualitative study was to explore the process of identity construction in early preschool age, in a multiethnic context and how this entire process translates into child wellbeing and their further educational path.

\section{Research Questions}

The research questions this study followed up upon include:

1) What is the process of identity construction in early preschool age?

2) How is children's wellbeing affected by parents' desire to expose them to a certain culture, other than the one the children were born into?

3) How natural is learning a foreign language for children, given a multiethnic space characterized by adversity and disparities such as "them"-"us"?

4) What are the potential outcomes of the phenomena in question?

\section{METHODOLOGY}

Research Design and Participant Selection

The study used a qualitative approach to explore the process of identity construction and the child wellbeing in the community of Cristian. It is a limited case study that comes under the category of socio-cultural anthropology research.

Purposive sampling was used to select participants. In the village of Cristian there is a single public kindergarten, that also includes a German department. For the 2014-2015 school year, a total of 70 children were signed up for kindergarten; the children are divided into four groups, one of which is German-taught. The kindergarten is a normal-schedule one (4 hours/day) and is a state institution. The German department class is headed by a single teacher. The teacher was the one 
to assess 15 children of the German group (age 3-6; 4 girls and 11 boys; 2 children coming from mixed families and 13 from Romanian families).

We solicited and obtained the written consent from all parents of the children involved. We also obtained the written consent from the kindergarten Management to carry out the study. Each of the interviewees (parent, teacher, and priest) gave their consent for audio-recording and using the data offered solely for the purpose of the study.

\section{Data Collection and Analysis}

We used data triangulation in order to increase the validity of our study.

In order to study child wellbeing, we administered the SDQ - Strengths \& Difficulties Questionnaires. The Strengths and Difficulties Questionnaire (SDQ) is a brief behavioral screening questionnaire about 3-16 year olds. The test asks 25 attributes, some positive and others negative. These 25 items are divided between 5 scales: emotional symptoms (5 items), conduct problems (5 items), hyperactivity/inattention (5 items), peer relationship problems ( 5 items), pro-social behavior (5 items).

All five scales include items for determining the child wellbeing in the group environment. The questionnaire targets the empathy level, the state of happiness or depression, the relationship with the classmates. Each item is a check-point for child wellbeing. In what concerns the validity of the questionnaire, the lowest Cronbach's Alpha was. 845 for the Pro-social Scale and the highest referred to the Conduct Problems Scale (.972). Data were interpreted using SPSS.

In order to fill in the data and for a better understanding of the phenomenon, we also conducted three semi-structured "in-depth" interviews on the main educational representatives and identity construction factors: parent, kindergarten teacher and priest. Member checking was used during the interview process to ensure the validity of the received data.

Participative observation was also used to complement the findings and the observation protocol included: the general spoken language, the atmosphere in the classroom and the language used in expressing emotion. Findings from interview and participative observation were interpreted using content analysis.

The hypothesis underlying the study is that the wellbeing of the Romanian children, residing in a multiethnic locality, registered in a German tuition class, is being affected by the discrepancy between the transmission of the ethnic-cultural information deriving from the family environment and educational environment.

\section{RESULTS AND DISCUSSIONS}

School is a crucial identity formation agent. As we emphasized in the theoretical part of the article, exploring the ethnic identity elements, and the knowledge of the identity belonging are mechanisms necessary for the development of the ethnic identity. School, together with family, is a proximal environment for these mechanisms to function. And knowledge and the assumption of the culture heritage also by means of schooling, in addition to the education provided by the 
child's family, are necessary for the argumentation of a future desire of acculturation and affiliation to a new ethnic code. Therefore, school is an essential identity builder.

The sense of belonging is vital for the child wellbeing. It is also worth noting that only two of the 15 children of the German group come from mixed families (Romanians and Saxons), the others having both parents of Romanian ethnicity. After administering the SDQ test on all of the 15 children of the German group, the results were unexpected. All indices for assessing the child wellbeing, through the perception of the teacher who answers with regard to each child, have positive values. On a scale from 0 to 2 (where $0=$ Not True and $2=$ Certainly True), the averages of the reference intervals were as follows:

1) emotional symptoms (5 items): 0,187

2) conduct problems (5 items): 0,156

3) hyperactivity/inattention (5 items): 0,224

4) peer relationship problems (5 items): 1,833

5) pro-social behavior (5 items): 1,720

Therefore, the children in the group do not exhibit behavioral problems, no emotional issues stand out, and the hyperactivity level is low. The children seem to know how to communicate among themselves and have a prosocial behavior. The results obtained following the centralization of the data categorically refutes the work hypothesis. However, the data obtained from the interviews and the participative observation complement the SDQ test values, and broaden our field of comprehension of the child wellbeing assessed by means of these five scales.

The first thing noted when entering the group classroom is the fact that all children speak Romanian, not only among themselves, but also when addressing the teacher. Throughout the period of the study, the atmosphere is relaxed, the children definitely feel safe in the group classroom, they are smiling and enjoying the time spent at the kindergarten. The data obtained after the SDQ testing are verified through participatory observation. We are still trying to thoroughly understand what builds the high level of wellbeing.

The German tuition group teacher is of Romanian ethnicity, has a twelve year work history in the educational field. She confesses to us that she only speaks German at kindergarten. Since her family does not speak the language, she has no one to converse with at home. She began her German language studies in the $2^{\text {nd }}$ grade. We believe this data to be important because, at this educational level, the teacher has a great influence on the entire knowledge transfer and child formation process. The teacher is a training vector by means of her whole experience and belonging.

When asked about her perception of the Saxons, the teacher tells us about her personal experience in contact with her childhood Saxon neighbors. She describes them as being more private, more recluse, and not accepting people in their yard. The exclusivity of the Saxons from her childhood period stirs up her curiosity and becomes a motivation for her further personal growth. Although she admits that at first she felt compelled by parents to attend a German tuition class, along the way she identified with the German ethnic group more and more and continued her studies within the German department. 
Returning to the group of children and the process of education, we learn that for the German department there is a special curriculum, which focuses on the language and communication field. However, the curriculum makes no direct references to specific content of the German ethnic culture. It rests at the discretion of the teachers to choose the content items: stories, tales, poems, songs, etc. The annual, weekly, daily planning is largely filled in Romanian and it is only the name of the activities that are noted in German. The teacher is dissatisfied with the lack of a methodologist to help her clarify these issues.

As regards the German culture elements, the teacher claims that any specifically cultural German activity is strongly substantiated to the children. The approach is such as: "I explain to the children, and they go home and explain further." To be noted: the school's function of catalyst for education and the function of exploring the ethnic elements. Except that for these children, exploring means passing into the cultural elements of another ethnicity, different from their native one, and transmitting it further would imply taking home, in the Romanian family, the message captured at kindergarten. With regard to the knowledge of the ethnic German culture elements, the teacher confesses: „In the beginning, I did not know a lot, either." ${ }^{5}$ She claims to attend various courses held by the German Forum and to collaborate with her colleagues in terms of learning and understanding the Saxon events.

We note the collaboration between the kindergarten and the Evangelical Church. The involvement of the church in children's education is often brought into discussion. And particularly, the involvement of the local evangelical priest whose objective is also that of explaining the content related to the particular cultural elements and religious holidays specific to the Saxon ethnicity. A reported example is the feast of the lanterns on Saint Martin's Day. The children are taken inside the evangelical church and they are explained the history of this holiday. When asked what language the priest uses when addressing the children, the teacher answers: "He explained them in German. But most of them are Romanian. (...) At a certain point, he realized they didn't understand, so he explained them in Romanian. The following year, he explained them in Romanian." 6

In making up her planning, the kindergarten teacher includes all specific Saxon religious events. The activities are carried out in partnership with the church. The teacher admits that she also refers to the events in Romanian culture, such as Mother's Day, celebrated on March 8, and not in the month of May, as Saxons celebrate it. Therefore, the specific Romanian ethnicity holidays are also remembered.

The children's level of understanding German is, in the teacher's view, unsatisfactory. She tells us about the strategy used by the children, which she has observed over several generations. It so happens that the group of children complies with the tasks expressed in German, being guided by one or two children in the group who know the language very well. They are usually part of Saxon or mixed families, who also use German at home. They understand the teacher's message and explain

\footnotetext{
G. Olaru (personal communication, February 10, 2014)

G. Olaru (personal communication, February 10, 2014)

G. Olaru (personal communication, February 10, 2014)
} 
to their classmates directly, by translating it into Romanian, or indirectly, by fulfilling the task, while their peers imitate them. The disadvantage is that "at one point, they stop listening to the whole message." 7 The children rely on the colleague who knows what is to be done and are no longer motivated to decode the request in German. They pick the easier or more natural way. Having this option, they remain inside the comfort zone and their state of wellbeing is not affected.

The teacher associates the children's increase in the level of confidence with the level of German language comprehension. Taking the discussion to a deeper level, the teacher talks about her requirements in terms of German language learning. At the beginning of her teaching experience, her expectations related to speaking the German language were higher. However, there was one incident that changed her expectations. One of the children came to her with the intention of telling her he needed to go to the toilet. The teacher asked the child to address her in German, and because he did not know how to express the sentence in German, the latter froze and failed to reach the bathroom in time. The incident submits to reason the teacher's entire approach. Children do not feel constrained, frustrated by not knowing the German language because no stress is placed on this matter. Learning from this incident helped to shed light upon the teacher's vision of conducting this process of training, education and insight into learning the Saxon ethnical elements. The language is perceived by the teacher as a breakthrough into the Saxon universe, but by acknowledging the level of frustration and the blockages that a child might experience, she lowers the standards and compromises by straying from ethnical exploration in favor of the wellbeing of children. Naturally, such an incident could have occurred due to various reasons. A shy child may freeze even when required to speak their mother tongue. The reason for his moment of inhibition when faced with the request to speak another language is the teacher's very decision of lowering her standards with regard to learning the German language, from that point of her career and up to the present. She became aware of how inhibited, frustrated and scared a child can be, when unable to express their basic needs in the language in which she considers natural to be expressed. Regarded through this incident and the teacher's subsequent educational approach, the children's state of wellbeing, as drawn from the applied test, has another rationale.

While talking about continuity in German language studies, the teacher estimates that only $20 \%$ of the children will pass on to the next level of the German department. "First of all, they cannot afford it financially, and secondly, there's the transportation." ${ }^{8}$ The children would need a constant companion to guide them on their way to school.

Another problem that the teacher notices is the reduction of seats along with the transition to the next levels. The selection for school enrolment is stricter as regards knowledge of the German language.

When asked to talk to us about the parents in the group, whether she noticed any difference in the Saxon ones as compared to the Romanian ones, the teacher

\footnotetext{
G. Olaru (personal communication, February 10, 2014)

G. Olaru (personal communication, February 10, 2014)
} 
begins by describing the qualities of the firstly listed. They are "more outgoing, their approach is more personal." 9

The Saxon parents or the mixed families are considered a special category. They are something else, in comparison with Romanian parents. The same distinction is also made in the case of teacher's colleagues, depending on their ethnicity. The openness, the lack of prejudice, the outgoingness are qualities associated with the colleagues from the German department.

The respondent acknowledges the attitude of her kindergarten colleagues, which consider her a part of a special category. She considers they are more special and are guided by different principles. We notice the sense of pride when exposing this view. Membership to the group of teachers from the German department is being perceived as a mark of professional superiority.

The pride associated with belonging to the Saxon ethnical group is also being felt among Romanian parents. Although not German language speakers, they participate in the activities that their children are involved in. "Although we didn't understand a word, we were present." 10 The description of the Saxon community members indirectly motivates the parents' preference for the German school: "(The Saxons) are highly regarded and have always been highly regarded, they were hardworking and respectful people, who primarily respected themselves, and then their neighbors." ${ }^{11}$ We capture the admiring tone of the responses that aim to describe the Saxons ethnicity.

In the received descriptions, we synthesize the order, the rigor and the strictness of the German educational model. These characteristics do not have a negative connotation. On the contrary, they are seen as factors of success, both in school life, and on a daily basis. "There were only Saxons living on my street. On Saturdays, at seven o'clock in the evening, everyone went out and swept the front of their gate."12 The image of this description is an example of the Saxon organization, vision and behavior, which remained in the minds of the parents, since their childhood. The essence of these images is projected into the Romanian parent's wishes to educate their children.

It is interesting to compare the rigor of the educational model as seen through the eyes of the Romanians, with the one lived by a Saxon child. "I had to stand still $^{\prime 13}$ is how the interviewed priest describes the memory of his participating in the religious sermons which he strictly used to attend. Which is in contrast to the Romanian children who, in his opinion, are more undisciplined, and have no patience. The priest makes a deeper analysis of the differences between the Romanian children and the Saxon ones. He speaks about the difference between East and West, as background for the ethnic code.

The interview with the evangelical priest of the village complements the image on the phenomenon and highlights the advantages and disadvantages of Roma-

\footnotetext{
G. Olaru (personal communication, February 10, 2014)

M. K. (personal communication, February 10, 2014)

M. K. (personal communication, February 10, 2014)

M. K. (personal communication, February 10, 2014)

U. Seidner (personal communication, February 11, 2014)
} 
nian ethnicity children affiliated to the German ethnicity through school. He is of Saxon ethnicity and administers three neighboring communities, among which is the village of Cristian.

We observe his involvement in various projects in which the children of the community take part. The relationship between school and church is perceived as important in his attempt to keep the Saxon culture alive. We are being offered clear examples of child involvement, regardless of their religion and ethnicity, in religious-themed events such as the Christmas play, in which 26 children took part last year, out of whom 10 were Orthodox. The example does not stand out through its numerical value, but through the idea of openness and acceptance.

The priest talks about a series of activities that involve the children from the community. He has a special view of transmitting the ethnic code. He talks about the living pedagogy. By means of various projects, he visits, together with the teenagers of the community, places filled with meaning and resonance in the history of the Saxons. "The children go home and pass the story on."14 We return to the idea of an educational catalyst in terms of preserving and exploring the ethnic code. Except that, once again, the ones bearing the message are, for the most part, Romanian children.

When asked whether he notices any differences between the children belonging to the two ethnicities, the priest declares that he cannot make a comparison precisely because there are no Saxon children in the community. However, he mentions the Saxon educational model of his grandparents: "Our grandparents were strict. They did not use violence, but if they said one thing, it had to be done."15

When asked if a Saxon is able to preserve the features of his ethnicity while living among Romanians, the respondent agrees with this statement only if we discuss adults. As regards the Saxon children who live in Romanian communities, the prerequisite for them to preserve their Saxon identity is knowledge of the language.

The priest's view as concerns the phenomenon of Romanian children learning in the German department is clearly defined by the expression: school track as to accede to the German ethnic group. The Romanian children, who are the influence of the parents' admiring perception, are being pushed to assimilate a cultural ethnic code that not only differs from the native one, but it is also competing with it.

\section{CONCLUSIONS}

The phenomenon of signing up Romanian children for the German department is present in all these localities in which the German School exists. In the light of the ethnic identity constructivist theory, we can speak of the construction and reconstruction of identity since childhood years. The reflective suggestion of this study case does not doubt the possibility that the Romanian children should be able to go through an identity reconstruction by means of German schooling. The tackled issue is child wellbeing within this constructivist process and its eventual purposefulness. Because, according to the teacher's assessment, only a small

$14 \quad$ U. Seidner (personal communication, February 11, 2014)

15 U. Seidner (personal communication, February 11, 2014) 
number of children would get to continue their studies at the German department. For most of them, the Saxon experience (at least by means of education) may be brought to a halt at the end of the 3 or 4 years of kindergarten.

The present case study indicates that in the commune of Cristian, children do not undergo a brutal process of affiliation to the Saxon ethnicity. The educators who contribute to their Saxon education make various compromises, for different reasons: either they, themselves, are not sufficiently affiliated to the Saxon ethnicity (there is the example of the Romanian ethnicity teacher, which is common among the German department teachers), or they make a compromise when it comes to speaking Romanian (the children use the Romanian language in the kindergarten space; no stress is put on learning the language; in order to make himself understood, the priest offers explanations in Romanian). Therefore, the children enjoy themselves, they learn things that are different from the ones at home and do not feel constrained to speak another language. Nonetheless, they feel the difference between the group they have been signed up to, and the groups with Romanian tuition. They feel special, privileged, and during joint activities they are proud to be part of the German department group. Can a child be proud of such an affiliation or is the sense of pride just and extension of the parental perception?

Aiming at the purposefulness of the phenomenon, we have two potential outcomes. There will be children within this group who will continue their studies in the German department, and children who will continue their studies, for reasons stated throughout the paper, in the Romanian department. Let us note the advantages and the disadvantages of a Saxon experience in kindergarten.

The first category will seriously hit the language barrier. In school, where the competition for seats in the German department will seriously sort out applicants, the language knowledge level will be higher. Putting aside the small number of seats and the parents' financial reasons, this triage is one of the serious reasons why children will not be able to continue their studies in the German department. But if they pass over this barrier, they will work harder and more seriously to learn the German language and this breakthrough will help them move along on their German identity construction path.

The second category of children (that is, the larger part of the group), will pass into the Romanian department. This is where they will resume adapting to the native ethnic code. It may seem easy and natural. But it may also signify failure. Particularly in the context of the admiring perception of the Saxon values. They will be the ones who failed to continue their path of the German school. Three years, the period spent in kindergarten, do not seem a lot. But when it comes to childhood years and the first three years of kindergarten education, this period is of great importance. And the echo that the childhood years have into the adult life is no longer argued nowadays. During this period, the children in this category will borrow those attitudes, behavior and beliefs that make a difference between them and us. And they will have to use these to reintegrate in new, yet old ethnic school groups, that is, those groups of native belonging. The projection of these children's wellbeing should be kept in mind. It is the final reflective element of the present study case. Are these three years to be ignored when it comes to construc- 
ting the identity of the Romanian ethnicity children? Should parents consider the changes in the cultural code, their impact in the early identity foundation and the real chances of completing the educational path, so that a change in the cultural ethnic code would not represent a compromise of childhood?

Interesting to be mentioned is also the compromise of the Saxon minority by accepting the entire discussed phenomenon. Under the admiring influence of the ethnicity they have been coexisting with for over 870 years, the Romanians direct their children towards The German School. But here, it is not Saxon that is being spoken (the Saxon dialect differs from the German language), and the opportunities, also for those of Saxon ethnicity, are envisioned in Germany, or in connection with Germany (jobs, studies, etc.) and not Transylvania, the Saxon land. The irony and, at the same time, the drama of the Saxon minority, is that the discussed phenomenon does not increase the number of the Saxons, although it is through them that The German School has become a standard of education in Romania. In the best of cases, there will be an increase in the number of evangelical confirmers, as a result of a larger number of teenagers (from among the children who continue their studies within the German department) being associated with the elements of the evangelical religion popular through the German ethnic code. But being an evangelical does not imply being a Saxon.

\section{REFERENCES}

Bourhis, R., Sachdev I. (1984). Vitality perceptions and language attitudes: Some Canadian data. Journal of Language and Social Psychology, 3, 97-126.

Clanet, C. (1993). L' interculturel: introduction aux approches interculturelles en education et en sciences humaines. Toulouse: Presse Universitaire du Miral.

Giles, H., Johnson, P. (1987). Ethnolinguistic identity theory: A social psychological approach to language maintenance. International Journal of the Sociology of Language, 68, 69-99.

Giles, H., Williams, A., Mackie, D. M., Rosselli, F. (1995). Reactions to Angle- and Hispanic-American-accented speakers: Affect, identity, persuasion, and the English-only movement. Language \& Communication, 15, 107-120.

Goodman, R. (1997). The Strengths and Difficulties Questionnaire: A Research Note. Journal of Child Psychology and Psychiatry, 38, 581-586.

Kagitcibasi, C. (1996). Family and human development across cultures: A view from the other side. Mahwah, New Yersey: Lawrence Earlbaum.

Phinney, J. S., Devich-Navarro, M. (1997). Variations in bicultural identification among African American and Mexican American adolescents. Journal of Research on Adolescence, 7, 3-32.

Phinney, J. S., Romero, I., Nava, M., Huang, D. (2001). The role of language, parents, and peers in ethnic identity among adolescents in immigrant families. Journal of Youth and Adolescence, 30, 135-153.

Statham, J., Chase, E. (2010). Childhood Wellbeing: A brief overview. 2-10. Retrieved from http:// www.cwrc.ac.uk/documents/CWRC_Briefing_paper.pdf

Tajfel, H., Turner, J. (1986). The social identity theory of intergroup behavior. In: S. Worchel, W. Austin (Eds.), Psychology of intergroup relations. (pp.7-24). Chicago: Nelson-Hall.

Zarate, G. (1986). Enseigner une culture étrangere. Paris: Ed. Hachette. 